\title{
Training Program Efficacy in Developing Health Life Skills among Sample Selected from Kindergarten Children
}

\author{
Reham Mohammad Al Mohtadi ${ }^{1} \&$ Habis Sa'ad Al Zboon ${ }^{1}$ \\ ${ }^{1}$ Curriculum \& Instruction Department, Al-Hussein Bin Talal University, Ma'an, Jordan \\ Correspondence: Reham Mohammad Al Mohtadi, Curriculum \& Instruction Department, Al-Hussein Bin Talal \\ University, Ma’an, Jordan. E-mail: Jordanian81@hotmail.com
}

Received: January 1, 2017

Accepted: January 17, 2017

Online Published: February 13, 2017

doi:10.5539/jel.v6n2p212

URL: http://doi.org/10.5539/jel.v6n2p212

\begin{abstract}
This study drove at identifying the training program efficacy in developing the health life skills among sample selected from Kindergarten children. Study sample consisted of 60 children of both genders, ages of which are ranged from 5-6 years old. We have applied herein the pre and post dimension of health life skills scale; consisting of 28 Paragraphs among the study sample. The training program, which was prepared to measure the health life skills, has been applied to training group individuals. The collected outcomes referred to statistical significance differences in the study individuals' performance, on health life skills scale, which are attributed to group, in the favor of experimental group. Moreover, the outcomes referred to differences of statistical significance attributed to gender in the favor of females. The collected outcomes have been discussed and further the study concluded some recommendations.
\end{abstract}

Keywords: training program, health life skills and children of Kindergartens

\section{Introduction}

Attention to Childhood becomes one of the standards which the communities development and progress is measured thereby. Our era requirements are connected basically to various life skills, which allow adaptation thereof with all witnessed variables. Life skills which the child needs nowadays are considered more complex and diverse, under the technological development which all current life aspects are witnessing. The foregoing requires more outreach as to life skills which shall qualify the children to adapting and coexisting with their surrounding environment. This, of course, shall be reflected on developing positive trends towards themselves, and further to gain others appreciation.

Al Sharqawi (2005) referred to the life skills development importance in the early childhood stage, as it is the basis which its future is established thereon. From this point, helping children becomes vital to adapt with its community and thence providing him with skills to face problems he may be subject to and solve thereof properly.

Preparing the child to live and training him to perform life skills, imposes the educational institutions to consider the foregoing through teaching methods and used programs. This shall, indeed, help the child to develop and grow equipped with skills derived from his needs in comfortable sphere and active environment free from complexity in order to display his accurate personality (Mahmoud, 2005).

Mustafa (2005) also added that traditional education negatives is represented by ignoring child education of life skills, in pre-school stage which shall offer them abilities and expertise that help them to face contemporary and future challenges. Moreover shall realize preparing qualified children to deal with community individuals and being aware of various professions importance which they shall practice in future.

In fact life skills include various personality trends, as it focus on mental component through collecting information and ideas that help children to study such phenomenon or problem and set out solutions and alternatives. Also it focuses on emotion and emotional component as the individual selects certain behavior from others. Lastly it concentrates on the skilled behavioral component through providing the individual with skills that help him to carrying out various skills. 


\section{Study Theoretical Framework}

\subsection{Life Skills Concept}

Henger (1992) defined this issue by pool of skills relating to child environment as well as cognitive, values and trends related thereto which the child learn and thence seek to build his balanced \& integrated personality that enable him to hold responsibility and becomes good citizen.

While Jones (1991), he defined life skills, as pool of operations and procedures through which the individual can solve certain problem, facing challenging issue or perform amendment on his life scopes.

Life skills are considered life Signs and preparations which are needed to develop students abilities to face stands and challenges in their life and community, to improve life quality and type through developing the required skills; such as health skills, skills which help individuals to face environmental causes and issues (Department of Education, 2003).

As for Health life skills, these skills are those which are connected to necessary knowledge, values and trends which enhance the child positive behavior towards personal and common health, and further help him to live his life free of diseases, mentally, socially and psychologically balanced in healthy community (Baqmi, 2012).

\subsection{Life Skills Classification}

Life skills are not limited to certain list, as its classifications are variable based on various communities and cultures. Moreover, such skills differ due to lack of agreed lists among researchers depending of the domain difference of each researcher. Mazen (2002) classified thereof to dealing skills with surrounding environment, Health care skills, healthy nutrition skills, normal children skills, environmental activity skills. While Fischer (1991), he classified life skills as; personal growth skills, health skills, nutrition skills, citizenship skills, communicating skills and consumption skills. Allolo (2005) set out his classification as to life skills; i.e., preventive skills, health skills, nutrition skills, environmental skills and manual skills. On the other hand, Hejazi (2006) set out classified thereof into two types, survival skills; skills that maintain individual life; health skills, dealing with environment, daily skills. Second type is growth and development skills; skills with others, self research skills, consumable outreach, time management skills, and solve problems skills.

\subsection{Life Skills Particulars}

Omran and others (2001) defined life skills particulars as follows:

1) Variable: including all physical and non-physical aspects connected with individual needs fulfillment.

2) Dissimilar means that it differ from community to another based on development degree, and it differs from time to time.

3) Depending on nature of exchanged relations between individual and community and each impact on another.

4) Help the individual to adapt and interact with various life stands to deal with new and developed methods.

\subsection{Life Skills Acquisition's Importance}

Life skills have special importance in is initial stages of learners' life. Students in this stage enjoy great wish to interact with the community and acquire actual expertise. This require from us to invest such particulars in the best manner, work to develop thereof through practicing such skills in early ages. The foregoing works to increase the learner's ability to practice such learning type through his future educational stages (Al Sayyed, 2001).

Life skills education includes applying life skills within actual stands which the child needs in his daily life. Each skill has its theoretical basis connected to sentimental aspect and performance one. The learner, once opportunity of learning skill becomes available to him he needs theoretical study that may enhance his mind and sentiment. He practices the skill based on his cognition and his sentimental structure which shall work to push him to learn such skill. If the learner has theoretical background on the skill, such background represents some cognition without affecting his sentiment. This, for sure, shall affect behavior type or skill performance and mastery (Askaws et al., 2005).

On the other hand, the individual master of certain skill, encourages him to promote such skill to open new work spheres, attain more gains, and convert to better level of the skill until reaching mastery degree of total skills to promote his vocational, social and psychological level (Askaws et al., 2005). 
Mahmoud (2005) added that life skills implication contributes in a way or another, to increase learner motivation and enhancement and then the learner becomes able to manage interaction with others, its environment and community.

\subsection{Life Skills Learning Stages}

There are several stages for children life skills development which are as follows (Al Jaberi, 1991):

1) Make sure that respective children need skill development.

2) Make sure that children understand the skill purport.

3) Prepare various stands to practice on such skill.

4) Make sure that children practice the skill they learned.

5) Skill practice continuity.

6) Creating educational sands that help children to practice such skill.

7) Using skill efficiently to generate auto natural behavior.

\section{Previous Studies}

Catherine (2002) concluded a study to help teachers in implementing skills educating program goals in terms of life, health of Kindergarten children up to $9^{\text {th }}$ Class 3 appendixes were used including planning tools, children informative skills and students' activities skills. The generated outcomes referred to necessity of developing life skills and health skills among children through applying some suitable activities and programs.

Hanley et al. (2007) and others aimed to evaluate educational program in developing and enhancing life skills among pre-school children in USA in order to overcome some problems; i.e., aggression and problematic behavior. The study sample was consisting of 16 children who were trained on life skills through scheduled activities (free play, food meals, role play). The generated outcomes referred to the educational program efficacy in developing life skills; as it worked to accrue $74 \%$ decrease in the children problematic behavior issue.

On the other hand, Al Baqmi (2012) study aimed to identify efficacy of puppets' theater in developing life skills in terms of my health and my safety of kindergarten children. Study community was formed from all children in Governmental kindergartens at Mecca City, 1433/1432H. The Semi-Experimental curriculum was used, and study sample consisted of 34 children of both genders. The study outcomes referred to the availability of differences of statistical significance between Experimental group children in pre and post application of the notice card to use puppet theater in developing life skills relating to health outreach at significant level of $0.05=\mathrm{a}$. $\mathrm{T}$ value came to read 55.811 in the favor of post application. Also differences of statistical significance were identified between SMA of experimental group children as to post and pre application of the notice on using Puppet Theater in developing life skills as to health outreach based on child gender variable (males and females) at significant level $0.05=\mathrm{a}$ as $\mathrm{T}$ value is calculated at 3.799 , in the favor of females.

Study concluded by Mohammad (2005) drove at marking out the efficacy of suggested program efficacy on comic \& written activities in developing some skills necessary for health and safety among mentally retarded persons who are able to learn (Morons). The foregoing study employed the experimental curriculum and applied thereof on sample selected from Al Wafaa Social Center students, Thafar Province, Sultanate of Oman; ages of such students are ranged from 8-12 years old. The study used skills list, necessary for morons' safety and health as well as notice card. The generated outcomes displayed that the suggested program has great effects in developing health and safety skills among morons.

\section{The Study Problem}

Paying attention to life skills in general and health life skills in particular are attributed to be a mode of change, which is required to be made in education issue. Children training shall be conducted on such skills that help them to interact with the various life situations. Many education personnel assured the importance of including such life skills in the curriculums; being important education outcomes and to be communicated to students in any academic stage; pre-school stage in particular. Children in this stage need such skills during their life stages, even in all their daily affairs in order to maintain integral and sustainable education.

In spite of the availability of educational curriculum that pays attention to developing the various skills of pre-school children, but there are many negative behaviors practiced by such children category, accompanied with much shortage in terms of health outreach thereof, whether of concern to general health (i.e., place cleaning, personal affairs, or food behaviors, etc.), as child fatness becomes to occupy the most risky problems at the 
global level, and it witnessed increased phenomena that causes much fear. As for Psychological health (fear, tension, deprivation feeling, lack of adaptation with others, etc.). Therefore this study is concluded to help children to adopt positive behaviors to help them to deal, effectively, with daily life challenges.

\section{The Study Questions}

-Are there differences of statistical significance $0.05 \geq$ a available between experimental group children marks average and those of controlling group in dimension application of health life skills scale attributed to training program?

-Are there differences of statistical significance between experimental group children marks average and that of controlling group in dimension application of health life skills scale attributed to gender?

\section{The Study Objectives}

-Indentifying the training program effectiveness in developing the health life skills among kindergarten children sample.

-Specifying the health life skills needed for Kindergarten students.

-Developing health life skills needed for kindergarten students.

\section{Study; Community \& Sample}

The study community consisted of all kindergartens students in Maan educational directorate. The sample number was 60 of both genders, 31 of which were selected randomly from Khadeejah Bent Khowailed mixed school, and 29 students from Maan fundamental mixed school, academic year 2015/2016. The following table displays study individuals distribution.

Table 1. Sample distribution on academic groups

\begin{tabular}{cccc}
\hline Gender/School & Males & Females & Total \\
\hline Khadeejah Bint Khuwailed & 13 & 18 & 31 \\
Ma'an fundamental mixed School & 15 & 14 & 29 \\
Total & 28 & 32 & 60 \\
\hline
\end{tabular}

They were divided randomly into two groups, first one is controlling group consisting of 30 students of both genders and experimental group of 30 students of both genders. They received training through depending on training program to developing their life health skills.

In order to ensure both groups parity before applying the raining program, we applied life health skills scale on the study sample in Pre mode, based on SMA, standard deviation and T test of independent sample for each group marks. Table 2 displays differences between Pre SMS of study sample in both experimental and controlling groups on the scale.

Table 2. Differences between SMAs/Pre measurement of study sample from both groups based on life health skills scale

\begin{tabular}{ccccccc}
\hline Group & Number & SMA & Standard Deviation & Free Marks & Total Value & Statistical Significant \\
\hline Experimental & 30 & 73.40 & 3,39 & 58 & 1.16 & 0.25 \\
Controlling & 30 & 72.48 & 2.06 & & & \\
\hline
\end{tabular}

The foregoing table, it is noticed that depending on $\mathrm{T}$ value, there were no differences of statistical significant between SMAs of study sample marks from both groups on the scale before applying training program which ensure both groups parity. 


\subsection{Study Methodology}

The researchers used semi-experimental curriculum that depends on both groups pursuant to design presented in Table 3.

Table 3. Experimental design of the study

\begin{tabular}{cccc}
\hline Group & Pre & Training & Post \\
\hline First Controlling & Life Health Skills & Without & Life Health Skills \\
Second Experimental & Life Health Skills & With Training & Life Health Skills \\
\hline
\end{tabular}

It is expressed mathematically as follows:

R $\quad$ G1 $01 \quad-\quad 02$

$\begin{array}{lllll}\mathrm{R} & \mathrm{G} 2 & 03 & \mathrm{x} & 04\end{array}$

\subsection{Study Tools}

1) Training program to verify life health skills measurement among children.

2) Notice Card for Life Health skills of Kindergarten child: it has been established by referring to the theoretical literature and studies handling life health skills among children; i.e., Al Baqmi (2012), Shrafat (2009). We have benefited from both studies tools in setting out Paragraphs of life health skills. The card consisted of (28) Paragraphs to measure life health skills. We have adopted Likert triple scale (as the high level (3) refers to child permanent practice of life health skills, medium (2) refers to child who displays interrupted practice of life health skills, while (1) means that the child does not practice lift health skills).

\subsection{Avelidaty of Tools}

The researchers have verified the internal consistency truth of life health skills scale by applying thereof on pilot sample consisting of 32 children from Kindergarten rather than this study sample. We have calculated Person correlation coefficient between each paragraph of the scale paragraphs and total degree of the scale. The following table explains the foregoing as follows:

Table 4. correlation coefficients between the degree of each paragraph of the scale with a total score

\begin{tabular}{cccccc}
\hline $\begin{array}{c}\text { Para } \\
\text { No. }\end{array}$ & $\begin{array}{c}\text { Correlation coefficient } \\
\text { At total degree }\end{array}$ & Significance level & Para No. & $\begin{array}{c}\text { Correlation coefficient } \\
\text { At total degree }\end{array}$ & Significance level \\
\hline 1 & 0.46 & Significant at 0.05 & 15 & 0.47 & Significant at 0.05 \\
2 & 0.42 & At 0.05 & 16 & 0.37 & At 0.05 \\
3 & 0.33 & At 0.05 & 17 & 0.49 & At 0.05 \\
4 & 0.56 & At 0.05 & 18 & 0.48 & At 0.05 \\
5 & 0.67 & At 0.05 & 19 & 0.52 & At 0.05 \\
6 & 0.29 & At 0.05 & 20 & 0.56 & At 0.05 \\
7 & 0.40 & At 0.05 & 21 & At 0.05 \\
8 & 0.40 & At 0.05 & 22 & 0.62 & At 0.05 \\
9 & 0.55 & At 0.05 & 23 & 0.46 & At 0.05 \\
10 & 0.21 & At 0.05 & 24 & 0.24 & At 0.05 \\
11 & 0.75 & At 0.05 & 25 & 0.33 & At 0.05 \\
12 & 0.46 & At 0.05 & 26 & 0.34 & At 0.05 \\
13 & 0.39 & At 0.05 & 27 & 0.56 & At 0.05 \\
14 & 0.29 & At 0.05 & 28 & 0.61 & At 0.05 \\
\hline
\end{tabular}


The above table displays that all the paragraphs are connected under statistical significant, to total degree of the scale which offers evidence as to the internal consistency truthfulness of the scale paragraphs.

\subsection{Reliability of Tools}

The researchers have verified the scale stability through applying thereof on initial sample consisting of 32 children based on Cronbakh Alpha equation, the internal consistency coefficient registered (0.80). Also we have verified the scale stability by using retail midterm way. In order to get ride of the impact of retail midterm way we have adopted Speerman brown equation. Stability coefficient value by using retail midterm way registered (0.84). The foregoing offered high degree of scale stability which allows the researchers to apply on the study sample.

\subsection{Statistical Analysis}

The researchers replied on the study questions through SMAs calculations and standard deviations of the sample individuals performance on life health skills based on group and gender variables. We have used also $T$ test of independent samples to figure out the training program impact.

\section{Study Outcomes}

The study aimed to identify training program efficacy in developing life health skills among kindergarten children. In order to achieve such aim, we prepared training program \& notice card to measure the life health skills among kindergarten children sample. Following presentation of study outcomes based on questions serial order.

\subsection{First Question}

Do statistical significant $(0.05 \geq a)$ differences are available between experimental group children and controlling group's SMAs in Post Application of life health skills scale that are attributed to training program impact?

To reply such question we have calculated SMAs and standard deviations of the study individuals performance on life health skills scale, we also used T Test of independent samples, as displayed in hereinafter Table 5.

Table 5. Differences between SMAs of Post measurement degrees of both experimental and controlling groups on life health skills scale

\begin{tabular}{lllllll}
\hline Group & Number & SMA & Standard Deviation & Free Degrees & T value & Statistical Significant \\
\hline Experimental & 30 & 74.04 & 2.96 & 58 & & 0.000 \\
Controlling & 30 & 40.08 & 3.60 & & 36.38 & \\
\hline
\end{tabular}

Table 5 refers to statistical significant differences at 0.05 level in the favor of experimental group on life health skills scale, which mean that children of both genders who learned how to use training program registered better achievement compared to students who did not receive training program. The foregoing outcome supports positive impact of using training program in developing the life health skills of kindergarten children. Reason of the foregoing is attributed to teaching methods used during carrying out the training program, as learning method via work and practice, tangible expertise through learner participation and its active role in situation planning, preparation and assessment thereof. Child integration in work and practice during learning shall lead to active learning issue, though which the learner shall gain new concepts and maintaining thereof (Barbara et al., 2006).

Mustafa (2005) also emphasizes that perceptual expertise offered to the child and followed discussions shall assist in expanding the child understanding as to skill and thence increasing motivation towards confirming and using thereof in his daily behaviors. Any pre-school child needs to promote his awareness and sensors via perceptual exciting that help in promoting its concepts. This shall work to encourage his cognitive needs and develop his life skills. This outcome came in line with study of Hanley et al. (2007) and Al Baqmi (2012).

\subsection{Second Question}

Are there any differences of statistical significant between SMAs of experimental group and those of controlling group children in Post application of life health skills scale that are attributed to Gender?

To reply such question we calculated the SMAs and standard deviations of study individuals performance on life health skills scale, also we used $\mathrm{T}$ test for the independent samples as displayed in Table 6 below: 
Table 6. Differences between SMAs of post measurement degrees of gender on life health skills scale

\begin{tabular}{ccccccc}
\hline Gender & Number & SMA & Standard Deviation & Free Degrees & Total Value & Statistical Significant \\
\hline Males & 28 & 56.6 & 17.9 & 58 & & 0.024 \\
Females & 32 & 58.4 & 17.4 & & 0.17 & \\
\hline
\end{tabular}

Table 6 indicates differences of statistical significant at 0.05 level attributed to gender variable in the females favor on life health skills scale. This could be back to that the fact that females are more attached to their mothers in this age stage than males. This grants the females bigger opportunity to follow up their mothers in their daily life affairs, thus they imitate their mothers in most of their daily behaviors. The foregoing is reflected on their imitation to life health skills and acquire great degree that males. This outcome comes in line with $\mathrm{Al}$ Baqmi's (2012) study.

\section{Recommendations}

1) Concluding similar studies as to this study, tackling developing other life skills of kindergarten children.

2) Holding seminars, lectures, forums and workshops for kindergarten teachers to promote their abilities how to use various training programs on promoting life health skills.

\section{References}

Al Baqmi, H. (2012). Efficacy of puppets theater to develop life skills as to my health and safety of kindergarten children in capital (MS thesis, not published). Om Al Qura university, KSA.

Al Sayyed, A. (2001). Using existing program on social structural learning form and its impact on achievement and development of life skills at $5^{\text {th }}$ Preparatory class students. In Studies in curriculums and methods of teaching (p. 1). Egypt.

Allolo, F. (2005). Life skills in Palestinian sciences of $1^{\text {st }} 2^{\text {nd }}$ Fundamental classes. In Palestinian child conference (pp. 658-678). Islamic University GAZA.

Askaws, P., \& Abdel Mawjood, M. (2005). Developing life skills of secondary education students within future curriculum frame. National center for educational and developmental researches, Cairo.

Barbara, R. F., Christopher, S., Michelle, N. E., Jack, M. F., Louisa, C. M., \& David, J. F. (2006). Impact of instruction practices in grades 1 , and 2 on reading and spelling achievement in high poverty school. Contemporary Educational Psychology, 31(1), 1-29. https://doi.org/10.1016/j.cedpsych.2004.11.003

Catherine, W. (2002). Health and life skills for kindergarten to grads 9: Guide to implementation, learning and teaching resources Branch. West deveonian Building.

Department of Education. (2003). Teacher's Guide for the development of learning programs policy guidelines. Pretoria: Department of Education, London.

Fischer, J. (1991). Life skills: What anethey social-science record (Vol. 16, No. 11).

Hanley, G., Heal, N., Tiger, J., \& Ingvarsson, E. (2007). Evaluation of Classwide teaching program for developing preschool life skills. Journal of Applied Behavior Analysis, 40(2), 277-300. https://doi.org/10.1901/jaba.2007.57-06

Hegner, D. (1992). Life skills across, the curriculum combined teacher student, basic books, newyork.

Hijazi, R. A. S. M. (2006). Spiral organization efficacy to promote life skills of classes students. In $10^{\text {th }}$ Scientific conference, scientific education, Current challenges and future visions G1 (pp. 347-389). Egypt.

Jaberi, A. (1991). Designing program to pre-school children (cooperation skills) (MS thesis, not published). Post studies institute, Ein Shams University.

Jones, R. (1991). Life skills. London, Cassel Educational ltd.

Mahmoud, A. R. (2005). Efficacy of suggested unit in children songs and poems to enrich related life skills. In Culture and Development Magazine. Egypt.

Mazen, H. (2002). Suggested form for life skills within comprehensive quality concepts, future vision. In $14^{\text {th }}$ Scientific conference, education methods on the light of performance concept (Vol. 1, p. 24). Egypt.

Mohammad, A. (2005). Efficacy of suggested program based on filmed and written activities to promote life for health and safety skills of Morons. In $9^{\text {th }}$ Scientific conference, scientific challenges in Arab world, 
diagnosis and solutions, Egyptian University for education (Vol. 21). Faculty of education, Ein Shams University, Egypt.

Mustafa, F. (2005). Child and life skills in Kindergarten and preparatory schools. Cairo, Arab Thought House.

Omran et al. (2001). Life skills. Cairo, Zahraa Library.

Sharqawi, A. (2015). Program to promote life skills of Riyadh children sample (MS thesis). Tanta University.

\section{Copyrights}

Copyright for this article is retained by the author(s), with first publication rights granted to the journal.

This is an open-access article distributed under the terms and conditions of the Creative Commons Attribution license (http://creativecommons.org/licenses/by/4.0/). 